Article

\title{
Analytical and Thermal Evaluation of Carbon Particles Recovered at the Cyclone of a Downdraft Biomass Gasification System
}

\author{
Nwabunwanne Nwokolo ${ }^{1, *}$, Sampson Mamphweli ${ }^{1}$ and Golden Makaka ${ }^{2}$ \\ 1 Institute of Technology, University of Fort Hare, P. Bag X1314, Alice 5700, South Africa; \\ smamphweli@ufh.ac.za \\ 2 Department of Physics, University of Fort Hare, P. Bag X1314, Alice 5700, South Africa; gmakaka@ufh.ac.za \\ * Correspondence: nnwokolo@ufh.ac.za; Tel.: +27-833-433-195
}

Academic Editors: Anthony I Okoh and Voster Muchenje

Received: 21 December 2016; Accepted: 14 April 2017; Published: 19 April 2017

\begin{abstract}
Gasification of biomass gives off syngas that is contaminated mostly by carbon particulates and tars. The degree of contamination is attributed to factors such as gasification process, type of gasifier and type of biomass material. Downdraft gasifier minimizes the production of tar to a tolerable limit for engine applications; however, carbon particles still pose a challenge particularly with the integration of a heat exchanger for the purpose of heat recovery from the product gas. The presence of carbon particles in the syngas does influence the heat recovery process and materials used in the recovery. Hence, there is need for the characterization of these carbon particles to ascertain their chemical compositions, thermal properties and morphological features. This study was aimed at evaluating the characteristic features of carbon particles recovered from the syngas stream during gas cleaning at the cyclone. The elemental analysis of the carbon particle samples was performed using energy dispersive $X$-ray spectroscopy. An electron beam from scanning electron microscopy was passed through the sample surface at a magnification of 1000x and an accelerating voltage of $15 \mathrm{kV}$ to determine the morphological features of the carbon particles. Their thermal properties were investigated using a thermogravimetric analyzer at a heating rate of $10^{\circ} \mathrm{C} / \mathrm{min}$. A weight loss of approximately $5.4 \mathrm{wt} \%$ was recorded at the maximum temperature of $900{ }^{\circ} \mathrm{C}$. Silicon, oxygen and carbon were found to be the dominating elements in the carbon particulate.
\end{abstract}

Keywords: carbon particles; cyclone; biomass gasification; particle elemental composition; downdraft gasifier; syngas

\section{Introduction}

Biomass is an organic matter that emanates from a wide range of sources and is generated through photosynthesis. Gasification is an efficient technological process used in converting biomass to clean syngas or liquid fuel. Gasification enables a more versatile use of biomass and accepts a variety of biomass materials. Previous studies on gasification have concentrated on enhancing gasification efficiency, carbon conversion efficiency and the production of gases such as carbon monoxide (CO) and hydrogen $\left(\mathrm{H}_{2}\right)$, which are combustible in nature. For this aim to be achieved, factors such as the type of biomass materials, gasifier type, type of gasification agent and operating conditions are important variables to be considered [1]. Carbon conversion efficiency is important due to its relation to the generation of carbon particles; it is defined as the percentage of carbon resident in biomass that is transformed to gases during gasification. It is determined from three parameters, namely: the mass of char remaining after gasification, the mass of biomass before gasification, and the carbon content of 
the biomass [2]. The amount of carbon particles that exit with the syngas stream during gasification is dependent on the carbon conversion efficiency.

Carbon particles refer to the unconverted portion of biomass material generated after gasification that is less reactive in nature. These carbon particles are separated from syngas with the use of a cyclone separator during syngas cleaning. Besides the cyclone, wet scrubbers and electrostatic precipitators are also used in the separation process of carbon particles. However, cyclone separators are widely used and in some cases multiples of such separators are used to improve the separation efficiency. The presence of carbon particles and other particulates, such as ash and bed materials, in syngas can cause plugging when they are deposited on the equipment [3]. To further process syngas into other chemical products, such as methanol, Fisher Tropsch oil, dimethyl ether and other applications, the reduction of particulates to a tolerable level is required. For instance, in an internal combustion engine application, particulate matter is required to be less than $50 \mathrm{mg} / \mathrm{Nm}^{3}$ [4]. Hence, once syngas is generated, it goes through some cleaning and cooling phases before being further utilized.

Generally, gasification technologies require the integration of a heat exchanger between the gasifier and the syngas cleaning unit. The functions of a heat exchanger may vary based on the gasifier type and cleaning requirements of the syngas. The use of wet scrubbers for both cleaning and cooling purposes has two major drawbacks; the generation of waste water and the inefficient utilization of energy [5]. These limitations are solved by the use of an alternative cleaning method known as hot gas cleaning. Although hot gas cleaning is still at the developmental stage, demonstrations so far show that this technique possesses the capability of enhancing the overall efficiency of the gasification system. However, contaminants such as carbon particles in the syngas can potentially cause erosion of metallic components and particle depositions during hot gas cleaning [6].

In the case of a heat exchanger, the deposition of carbon particles on its surface can inhibit the transfer of heat thereby causing instability in the operation of the gasifier [7]. Furthermore, this could lead to a blockage of the gas path around the heat exchanger and the transportation of corrosive species to heat exchanger. The deposition of carbon particles on heat exchangers is dependent on the nature of syngas flow and can occur through any of these routes; direct inertial impaction, Brownian diffusion, turbulent eddy diffusion, and thermophoresis. Direct inertial impaction is applicable to particles above $10 \mu \mathrm{m}$ in size, while smaller sized (below $10 \mu \mathrm{m}$ ) particles are associated with turbulent eddy diffusion, Brownian diffusion and thermophoresis [8,9]. The concentration of carbon particles and other contaminants in the gas stream is traceable to both the fuel characteristics (such as fuel type, particle size) and the gasifier configuration.

Gasifiers used for the purpose of gasification are broadly classified into either fixed bed, entrained flow and fluidized bed. Fixed bed is known as the conventional gasifier, with a bed of solid fuel that descends by gravity as gasification is taking place. These are characterized by long residence time, high carbon conversion, low ash carryover, and low gas velocity [10]. A fixed bed downdraft gasifier is termed suitable for engine and turbine applications due to its low tar production, which is in the range of $10 \mathrm{~g} / \mathrm{Nm}^{3}$ [11] Nevertheless, some unburned carbon particles still exit with the syngas stream in a downdraft gasifier. A study shows that the concentration of solid particles recovered from a biomass gasification plant was in the range of 3-10 wt \% of the solid fuel [12]. In another study that utilized wood chips as feedstock, the particulate matter recovered from the two-stage downdraft gasifier was mostly dominated by soot [13]. Furthermore, San Miguel et al. [14] investigated the characteristics of solid particles that were generated from an $800 \mathrm{~kg} / \mathrm{h}$ biomass gasification plant.

\section{Carbon Particle Theory}

The bulk of particulate matter from the gasification of biomass in a downdraft gasifier is constituted by solid carbon particles. These carbon particles vary in their compositions as well as sizes from less than $1 \mu \mathrm{m}$ to over $100 \mu \mathrm{m}$ [15]. Based on these sizes, also referred to as particle diameter, carbon particles are divided into fine and coarse particles. Particle diameter (dp) is a significant parameter used in describing the properties and behavior of particles. However, defining the diameter 
of particles is difficult in some cases due to irregularities in shapes of some particles. Two descriptions of particle diameter that stand out are Stokes diameter and aerodynamic diameter. Stokes diameter defines the diameter of a particle with similar terminal settling velocity and density, while aerodynamic diameter has similar terminal settling velocity and a particle density of $1 \mathrm{~g} / \mathrm{cm}^{3}$ [16]. The two diameters, aerodynamic and Stokes, are related by Equation (1):

$$
\mathrm{d}_{\mathrm{ae}}=\mathrm{d}_{\mathrm{s}} \times \sqrt{\frac{\rho_{\mathrm{p}} \mathrm{C}_{\mathrm{c}}\left(\mathrm{d}_{\mathrm{s}}\right)}{\rho_{0} \mathrm{C}_{\mathrm{c}}\left(\mathrm{d}_{\mathrm{ae}}\right)}}
$$

where $d_{a e}$ is aerodynamic diameter, $d_{s}$ is Stokes diameter, $\rho_{p}$ is particle density, $\rho_{0}$ is standard density with a given value of $1 \mathrm{~g} / \mathrm{cm}^{3}$, and $C_{c}$ is Cunningham slip correction factor [17]. The formation of particles during biomass gasification differ from that of combustion, and the mechanism of the formation for combustion is well-known and studied compared to that of gasification. In addition, the particle formation mechanism of fine- and coarse-mode particles is said to be different. Fine particles are formed through chemical reactions and homogeneous condensation and nucleation, while coarse particles are formed through mechanical processes. Their elemental compositions are also reported to differ. Potassium, sulphur and chlorine are mostly present in fine particles, while coarse particles are rich in calcium, aluminum, potassium, and silicon [18]. This is in agreement with the statement that different sized particles have different origins and are generated via different routes, and thus usually vary in chemical compositions and physical properties.

Three particle formation routes were identified in a study by San Miguel et al. [14]; firstly, particles formed as result of the progressive wearing down of carbonaceous biomass particles due to mechanical interactions inside the gasifier. Secondly, carbon particles formed through the condensation of gaseous organic molecules and are accompanied with the coagulation, agglomeration and aggregation of primary particles into larger solid particles. The third formation mechanism involves the emanation of inorganic components after complete gasification of carbonaceous fraction. Due to the generation of particles alongside syngas during gasification, syngas undergoes some cleaning processes before its subsequent use for energy, heat or chemical applications. The extraction of heat from hot syngas requires the use of heat exchanger devices, hence, the presence of carbon particles in the syngas is a concern.

Prior to the integration of a heat exchanger in the existing downdraft gasification system, an investigation into the physical condition, thermal reactivity and chemical composition of carbon particles contained in the syngas stream is required for long-term and economical operation of the heat exchanger and gasification plant. The deposition of carbon particles on the surface of a heat exchanger over time, as syngas passes through it during heat recovery, is detrimental to heat exchangers. These carbon particle deposits result in fouling which impacts the thermal and mechanical performance of the heat exchanger. Fouling impacts negatively on the heat exchanger, as it increases the overall thermal resistance and lowers the overall heat transfer coefficient. Hence, understanding the chemical composition as well as the thermal reactivity of these carbon particles will provide information on how these carbon particles will react with heat exchanger materials. This will also aid in the choice of a heat exchanger and in determining whether a direct or indirect type is suitable for a gasification plant. Therefore, the objective of this present work is to characterize the carbon particles (char) generated from gasification of wood in a downdraft gasifier. The sample carbon particles used for further characterization were recovered from the cyclone chamber of a gasification system.

\section{Materials and Methods}

\subsection{Carbon Particle Generation}

The carbon particle samples that were characterized for this study were generated from the gasification of pine wood in a $300 \mathrm{~N} / \mathrm{m}^{3}$ per hour downdraft gasifier installed at the village of Melani, 
Eastern Cape Province of South Africa. Figure 1 shows the schematic diagram of the downdraft gasifier system.

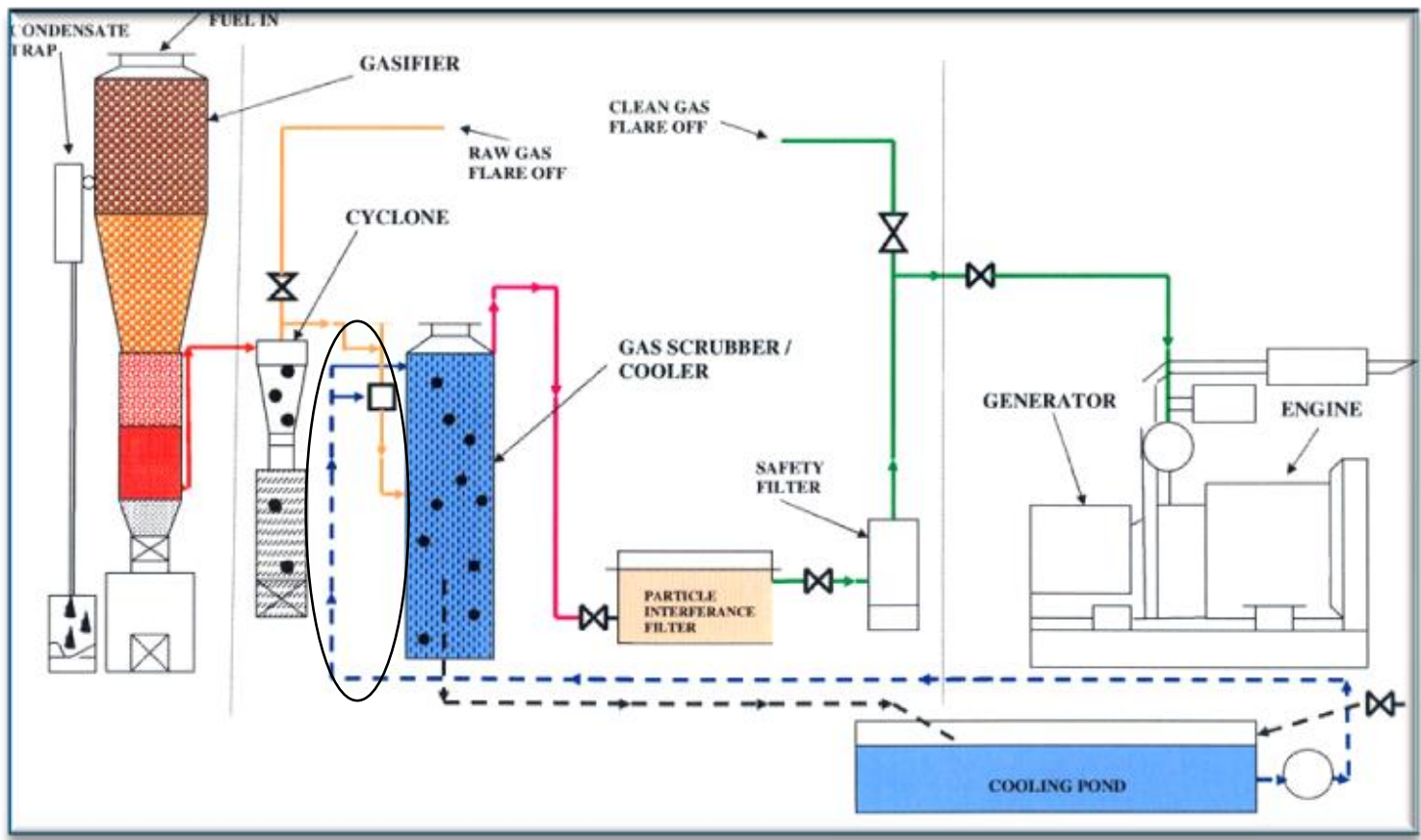

Figure 1. Schematic diagram of a Johansson gasification system.

Pine wood chips with a particle size of 7.5 by 6.8 by $4.3 \mathrm{~cm}$ were fed into the air-blown downdraft gasifier. A 2-kW centrifugal blower was used to simulate the engine suction before the ignition of the gasifier. The gasifier was then ignited through the ignition sleeve, kicking off the combustion process. As the combustion process begins at the combustion/oxidation zone, as shown in Figure 2, some chemical reactions take place between the chemical composition of the pine wood and air blown into the gasifier.

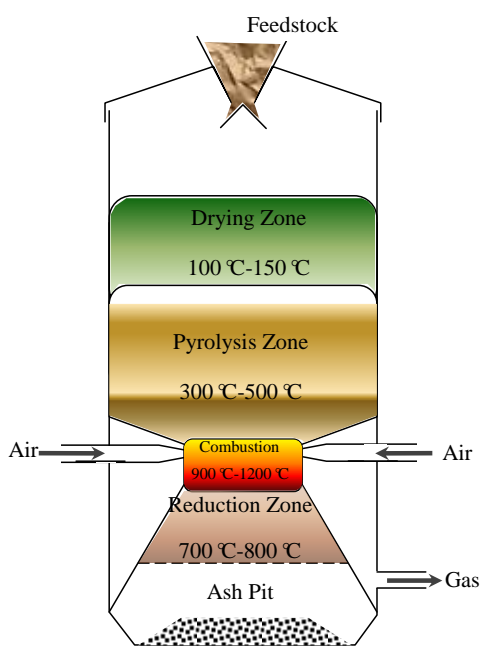

Figure 2. Reaction zones of the downdraft gasifier.

The necessary heat that drives the drying, pyrolysis and reduction processes are generated during the combustion process at the combustion zone. At the reduction zone shown in Figure 2, the carbon 
dioxide and water vapor from the combustion zone reacts with the hot bed of char particles, and this results in the production of syngas with suspended carbon particles. The chemical equation summing up the reactants and products that result from the gasification of biomass in a limited supply of air is given in Equation (2):

$$
\begin{aligned}
& \mathrm{C}_{n} \mathrm{H}_{x} \mathrm{O}_{y} \mathrm{~N}_{z}+m\left(\mathrm{O}_{2}+3.76 \mathrm{~N}_{2}\right) \rightarrow x_{1} \mathrm{H}_{2}+x_{2} \mathrm{CO}+x_{3} \mathrm{CO}_{2}+x_{4} \mathrm{H}_{2} \mathrm{O}+x_{5} \mathrm{CH}_{4} \\
& +x_{6} \mathrm{C}+(z / 2+3.76 m) \mathrm{N}_{2}
\end{aligned}
$$

The downdraft gasifier being air-blown (with an equivalence ratio of 0.29 ) resulted in a syngas with a calorific value of $6.3 \mathrm{MJ} / \mathrm{Nm}^{3}$, which exits the gasifier chamber within a temperature range of $400-500{ }^{\circ} \mathrm{C}$. Air-blown gasification results in the dilution of syngas with nitrogen gas due to the high content of nitrogen in the air. This in turn reduces the combustible component of the syngas that determines its calorific value. As the syngas stream with suspended carbon particles is discharged from the gasification chamber, it enters the cyclone dust collector (circled in the schematic diagram). At the cyclone, the suspended carbon particles collide with the cyclone wall and, with the help of gravity, inertia, and centrifugal forces, the particles are pulled down to the collection chamber where they are collected. Table 1 shows the ultimate and proximate analysis of the pine wood utilized.

Table 1. Proximate and ultimate analysis of pine wood [19].

\begin{tabular}{ccccc}
\hline Pine Wood & \multicolumn{4}{c}{ Proximate Analysis (wt \%) } \\
\hline MC & VM & FC & AC \\
14 & 67.72 & 17.88 & 0.4 \\
\hline \multicolumn{5}{c}{ Ultimate analysis (wt \%) } \\
\hline $\mathrm{C}$ & $\mathrm{H}$ & $\mathrm{N}$ & $\mathrm{O}$ \\
47.51 & 6.52 & 0.095 & 45.87 \\
\hline
\end{tabular}

MC-Moisture Content, VM-Volatile Matter, FC—Fixed Carbon, AC—Ash Content, $\mathrm{C}$-Carbon, H-Hydrogen, $\mathrm{O}-$ Oxygen, N-Nitrogen.

\subsection{Characterization Techniques and Instrumentation}

The morphological surface and elemental composition of the carbon particles were studied using a JSM-6390LV scanning electron microscope (SEM) and an energy dispersive X-ray spectrometer (EDS). JSM-6390LV is a high-performance SEM with a high resolution of $3.0 \mathrm{~nm}$. An electron beam from JSM-6390LV SEM was passed through the sample surface at a magnification of $1000 \times$ and an accelerating voltage of $15 \mathrm{kV}$ to determine the morphological features of the carbon particles. The sample was coated with gold for clear visibility of the surface morphology. The mineral constituent was determined using an X-ray diffractometer (XRD). The thermogravimetric analysis of the sample was performed using Perkin-Elmer TGA 7 (Norwalk, CT, USA). A sample weight of $10.9 \mathrm{mg}$ was placed in the analysis pan and nitrogen was used as a purge gas at a constant purge flow rate of $20 \mathrm{~mL} / \mathrm{min}$. The weight of the sample was then monitored by the precision balance as the sample pan gets heated in the furnace. The sample was held at $10^{\circ} \mathrm{C} / \mathrm{min}$ (heating rate) as it was heated from $20{ }^{\circ} \mathrm{C}$ to $900{ }^{\circ} \mathrm{C}$ and maintained for $1 \mathrm{~min}$ at $900{ }^{\circ} \mathrm{C}$. The weight loss by the sample and its derivative rate with respect to time and temperature were recorded as the experiment was ongoing. The heating value of the sample was determined in a previous experiment, and was established to be $35.3 \mathrm{MJ} / \mathrm{kg}[20]$.

\section{Results and Discussion}

\subsection{Morphology and Elemental Composition of Carbon Particles}

The morphology and elemental composition of carbon particles are of great importance due to the possible deposition of these particles on heat exchanger surfaces when extracting heat 
from particle-laden syngas. Figure 3 presents the SEM image and EDS spectrum of the carbon particles investigated.

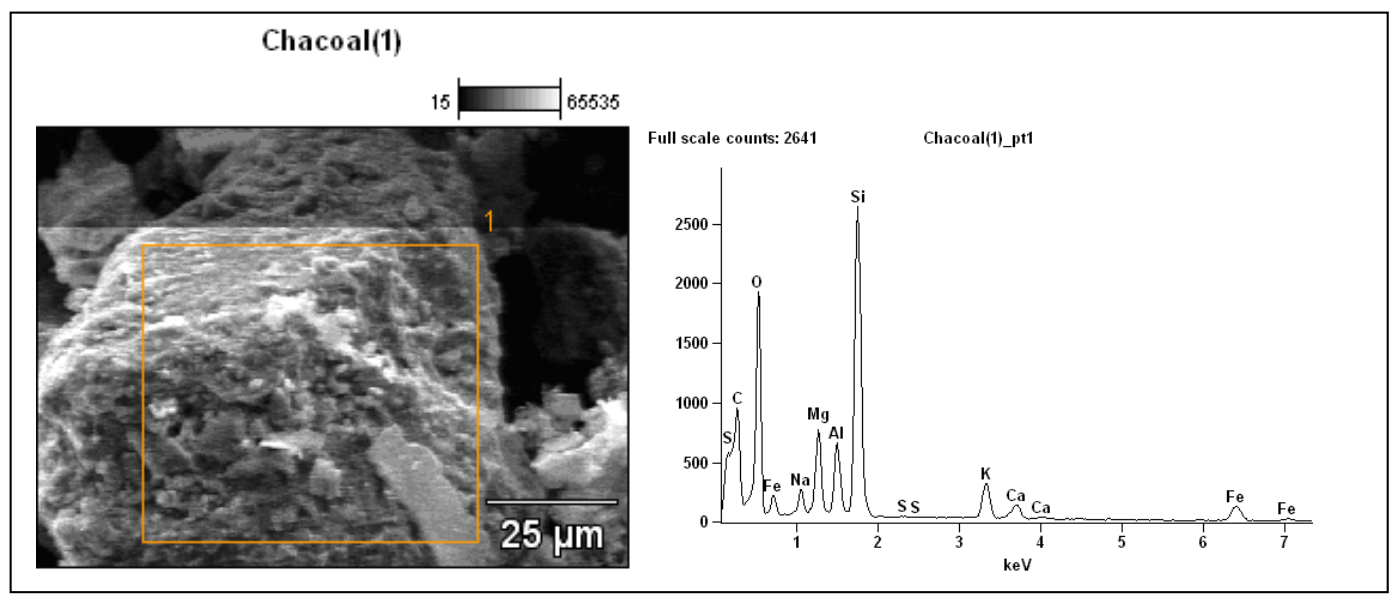

Figure 3. SEM image with Energy dispersive spectroscopy spectrum of carbon particles.

The morphological structure of the carbon particle sample presented in Figure 3 shows that they consist of different elements at varying concentrations in a lumped form. The lump of elements could be a result of condensation of gaseous organic molecules during gasification. The particle size of $25 \mu \mathrm{m}$ obtained for the carbon particles exceeds the minimum size reported by the World Health Organization that poses a threat to public health, due to the ease with which it can readily reach the respiratory tracts when inhaled [14]. Table 2 presents the elemental compositions of the carbon particles analyzed using EDS in combination with SEM.

Table 2. EDS analysis of carbon particles.

\begin{tabular}{ccccccccccc}
\hline & \multicolumn{11}{c}{ Element (wt \%) } \\
\hline PS $(\mu \mathrm{m})$ & $\mathrm{C}$ & $\mathrm{O}$ & $\mathrm{Na}$ & $\mathrm{Mg}$ & $\mathrm{Al}$ & $\mathrm{Si}$ & $\mathrm{S}$ & $\mathrm{K}$ & $\mathrm{Ca}$ & $\mathrm{Fe}$ \\
25 & 20.35 & 34.38 & 1.56 & 4.96 & 3.98 & 19.68 & 0.13 & 4.19 & 2.09 & 8.67 \\
\hline
\end{tabular}

From Table 2 it can be observed that carbon $(\mathrm{C})$ and oxygen $(\mathrm{O})$ are the only light elements that were detected from the sample. This is expected, bearing in mind that EDS has a low accuracy in the detection of light elements. Carbon and oxygen are significantly higher than the rest of the elements, with exception of silicon. High concentrations of oxygen and some other ions such as iron (Fe) and sulphate can lead to the corrosion of heat recovery equipment when carbon particles are deposited on them over time. Although it has also been reported that oxygen can sometimes play a protective role on the heat recovery equipment, by creating a passive film. However, at high temperatures this protective film is more likely to break down due to the lower rate of oxygen solubility [21]. Silicon (Si) was found in significant concentration (19 wt \%) as compared to sulphur (S), which was presented the lowest concentration $(0.13 \mathrm{wt} \%)$. This compares very closely with $16.1 \mathrm{wt} \%$ of $\mathrm{Si}$ and $0.2 \mathrm{wt} \%$ of $\mathrm{S}$ reported for large spherical particles of fine slag. However, the other classifications of fine slag, adhesive spherical fines, floccules, porous irregular particles, and coarse slag differed in the concentration of Si and S [22]. Silicon at present is reported to have no negative effect on heat recovery equipment, but sulphur does pose a negative threat, as it is listed as one of the ions that cause corrosion. Still, the sulphur concentration in the carbon particle was very minimal.

The presence of alkali and alkaline earth metals potassium $(\mathrm{K})$, sodium $(\mathrm{Na})$, magnesium $(\mathrm{Mg})$, and calcium $(\mathrm{Ca})$ could lead to the formation of deposits on heat recovery equipment surface when used in the direct contact heat transfer mechanism. In addition to these alkali and alkaline earth metals, chlorine is also identified as an important fouling facilitator on heat transfer surfaces [23]. Fouling 
leads to scale formation on the heat transfer surface, which consequently causes a decrease in heat flux and an increase in the temperature of the fluid that supposed to be cooled [24]. Corrosion and fouling are the two identified failure mechanisms that could occur if the direct contact heat recovery equipment used for recovering heat from the syngas is compromised by the presence of carbon particles in the syngas. Therefore, an indirect contact heat transfer mechanism was adopted for this study.

\subsection{Thermal Characteristics}

Figure 4 presents the weight loss of the carbon particle sample when it was heated in a thermo gravimetric analyzer [TGA] from a temperature of 20 to $90{ }^{\circ} \mathrm{C}$, and the derivative of the sample weight with respect to time. The heating temperature range represents a typical gasification temperature.

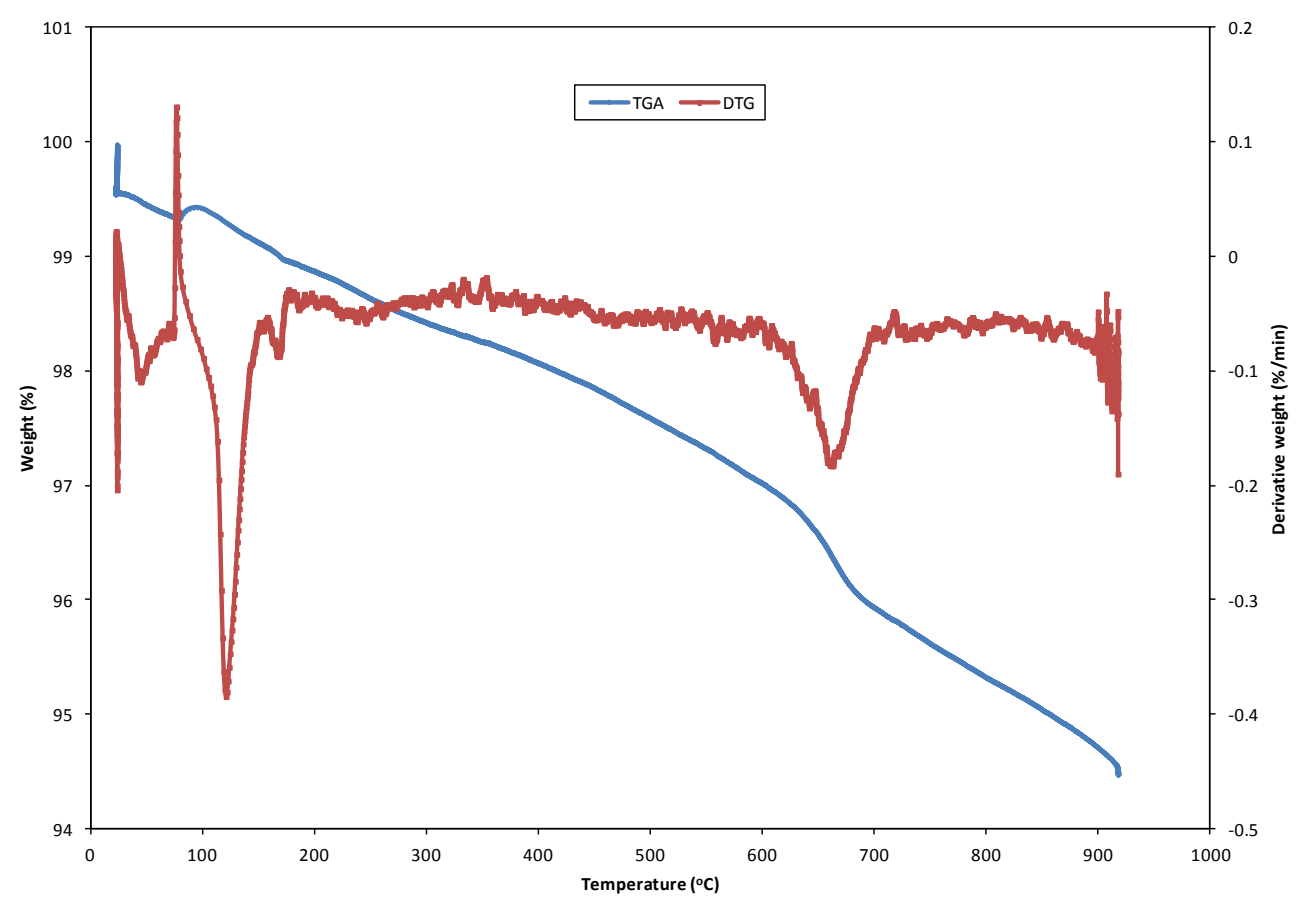

Figure 4. Thermogravimetric analysis and differential thermal analysis plot of carbon particles in a nitrogen atmosphere.

It is observed from Figure 4 that there was a slight change in the weight of the sample over the heating temperature range of $20-900{ }^{\circ} \mathrm{C}$. On average, a weight loss of approximately $5.4 \mathrm{wt} \%$ was recorded at the maximum temperature of $900{ }^{\circ} \mathrm{C}$. The overall $5.4 \mathrm{wt} \%$ weight loss observed in Figure 3 is slightly lower compared to the weight loss of $9.06 \mathrm{wt} \%$ recorded in another study at a temperature of $750{ }^{\circ} \mathrm{C}$ [14]. This indicates the high thermal stable nature of the sample (carbon particles). In addition, the moisture content of the sample was evaluated from a TGA residual weight of $0.4 \%$. The obtained moisture content was very insignificant, implying that nearly all the moisture in the pine wood (feedstock) was driven off during the gasification that led to the generation of the carbon particles. The low moisture content is very beneficial in terms of reduced energy utilization when it is reused as a feedstock in the gasification plant. Considering the temperature range $\left(250-600{ }^{\circ} \mathrm{C}\right)$ within which volatiles are usually released, it could be deduced from Figure 4 that the volatile matter content of the carbon particles is low. This is comparable to a commercial carbon black with a volatile matter content of $<1-5 \mathrm{wt} \%$ [25]. The differential thermogravimetric curve in Figure 4 shows three distinct peaks; the first two peaks were observed at a temperature range of $40-200{ }^{\circ} \mathrm{C}$ and the third peak occurred within $600-700{ }^{\circ} \mathrm{C}$. From the thermal degradation of the carbon particles shown in Figure 3, one can deduce that the fear of the carbon particles undergoing further degradation inside the heat recovery unit is minimal. 


\section{Conclusions}

Biomass gasification was carried out in a downdraft gasifier using pine wood as feedstock, and carbon particles in the syngas were collected at the cyclone bottom chamber. The analyzed carbon particles showed a low concentration of sulphur $(0.13 \mathrm{wt} \%)$, which is advantageous in terms of reduced sulphurdioxide $\left(\mathrm{SO}_{2}\right)$ emission. It was found that the presence of alkali and alkaline earth metals, such as potassium $(\mathrm{K})$, sodium $(\mathrm{Na})$, magnesium $(\mathrm{Mg})$, and calcium $(\mathrm{Ca})$, in the particles could lead to the formation of deposits on the heat exchanger surface when it is used to extract heat from a particle-laden gas. High concentrations of oxygen and some other ions such as iron ( $\mathrm{Fe})$ and sulphate can also lead to the corrosion of the heat exchanger equipment when carbon particles are deposited on them over time. Hence, this study suggests the use of heat exchangers that are highly resistant to corrosion in a gasification plant. In addition, a scheduled cleaning of the heat exchanger should be adopted once integrated into the gasification plant to avoid the accumulation of carbon particles on the surface due to the presence of alkali and alkaline earth metals within these particles. Lastly, carbon particles are inevitable byproducts of the gasification of biomass; hence the choice of heat exchanger material should be based on its resistance to corrosion.

Acknowledgments: The authors wish to acknowledge the Energy and Water Sector Education and Training Authority (EWSETA) for funding the study of which this article is a part.

Author Contributions: The design, analysis and writing of the manuscript were done by corresponding author, The manuscript was revised by Sampson Mamphweli and Golden Makaka.

Conflicts of Interest: There are no conflicts of interest. The funding sponsors played no role in the design of the study; in the collection, analyses or interpretation of data; in the writing of the manuscript, or in the decision to publish the results.

\section{Abbreviations}

$\begin{array}{ll}\text { SEM } & \text { Scanning Electron Microscope } \\ \text { EDS } & \text { Energy Dispersive X-ray Spectrometer } \\ \text { TGA } & \text { Thermogravimetric Analyzer }\end{array}$

\section{Chemical Formulas}

$\begin{array}{ll}\mathrm{CO} & \text { Carbon monoxide } \\ \mathrm{H}_{2} & \text { Hydrogen } \\ \mathrm{C} & \text { Carbon } \\ \mathrm{O}_{2} & \text { Oxygen } \\ \mathrm{Na} & \text { Sodium } \\ \mathrm{Mg} & \text { Magnesium } \\ \mathrm{Al} & \text { Aluminum } \\ \mathrm{Si} & \text { Silicon } \\ \mathrm{S} & \text { Sulphur } \\ \mathrm{K} & \text { Potassium } \\ \mathrm{Ca} & \text { Calcium } \\ \mathrm{Fe} & \text { Iron }\end{array}$

\section{References}

1. Acton, A.Q. Advances in Carbon Research and Application; Scholarly edition: Atlanta, GA, USA; ISBN: 978-1-481-66978-8.

2. Ahmad, M.I.; Alauddin, Z.A.Z.; Soid, S.N.M.; Mohamed, M.; Rizman, Z.I.; Rasat, M.S.M.; Razab, M.K.A.A.; Amini, M.H.M. Performance and carbon efficiency analysis of biomass via stratified gasifier. ARPN J. Eng. Appl. Sci. 2015, 10, 9533-9537.

3. Kumar, A.; Jones, D.D.; Hanna, M.A. Thermochemical Biomass Gasification: A Review of the Current Status of the Technology. Energies 2009, 2, 556-581. [CrossRef] 
4. Laurence, L.C.; Ashenafi, D. Syngas Treatment Unit for Small Scale Gasification-Application to IC Engine Gas Quality Requirement. J. Appl. Fluid Mech. 2012, 5, 95-103.

5. Woolcock, P.J.; Brown, R.C. A review of cleaning technologies for biomass-derived syngas. Biomass Bioenergy 2013, 52, 54-84. [CrossRef]

6. Villot, A.; Gonthier, Y.; Gonze, E.; Bernis, A.; Ravel, S.; Grateau, M.; Guillaudeau, J. Separation of particles from syngas at high-temperatures with an electrostatic precipitator. Sep. Purif. Technol. 2012, 92, 181-190. [CrossRef]

7. Ichikawa, K.; Kajitani, S.; Oki, Y.; Inumaru, J. Study on char deposition characteristics on the heat exchanger tube in a coal gasifier-Relationship between char formation and deposition characteristics. Fuel 2004, 83, 1009-1017. [CrossRef]

8. Gupta, R.; Wall, T.; Baxter, L. (Eds.) Impact of mineral impurities in solid fuel combustion. In Proceedings of the Engineering Foundation Conference on Mineral Matter in Fuels, Kailua-Kona, HI, USA, 2-7 November 1997; KluwerAcademic/Plenum Publishers: New York, NY, USA, 1999.

9. Kilgallon, P.; Simms, N.J.; Oakey, J.E. Materials for Gasifier Heat Exchangers; Power Generation Technology Centre, Cranfield University: Cranfield, UK, 2004.

10. Puig-Arnavat, M.; Bruno, C.J.; Coronas, A. Review and analysis of biomass gasification models. Renew. Sustain. Energy Rev. 2010, 14, 2841-2851. [CrossRef]

11. Martínez, D.J; Mahkamov, K.; Andrade, V.R.; Lora, E.E.S. Syngas production in downdraft biomass gasifiers and its application using internal combustion engines. Renew. Energy 2012, 38, 1-9. [CrossRef]

12. Knoef, H. Handbook Biomass Gasification; BTG Biomass Technology Group: Enschede, The Netherlands, 2005; ISBN: 978-90-810068-1-1.

13. Hindsgaul, C.; Schramm, J.; Gratz, L.; Henriksen, U.; Bentzen, J.D. Physical and chemical characterization of particles in producer gas from wood chips. Bioresour. Technol. 2000, 73, 147-155. [CrossRef]

14. San Miguel, G.; Domínguez, M.P.; Hernández, M.; Sanz-Pérez, F. Characterization and potential applications of solid particles produced at a biomass gasification plant. Biomass Bioenergy 2012, 47, 134-144. [CrossRef]

15. Hoffmann, A.C.; Stein, L.E. Gas Cyclones and Swirl Tubes: Principles, Design, and Operation, 2nd ed.; Springer: Berlin, Germany; New York, NY, USA, 2008; Volume 26, p. 422.

16. Hinds, W.C. Aerosol Technology: Properties, Behavior, and Measurement of Airborne Particles, 2nd ed.; Wiley: New York, NY, USA, 1999.

17. Morgalla, M.; Lin, L.; Seemann, M.; Strand, M. Characterization of particulate matter formed during wood pellet gasification in an indirect bubbling fluidized bed gasifier using aerosol measurement techniques. Fuel Process. Technol. 2015, 138, 578-587. [CrossRef]

18. Jöller, M.; Brunner, T.; Obernberger, I. Modeling of aerosol formation during biomass combustion in grate furnaces and comparison with measurements. Energy Fuels 2005, 19, 311-323. [CrossRef]

19. Nwokolo, N.; Mamphweli, S.; Meyer, E.; Tangwe, S. Electrical performance evaluation of Johansson biomass gasifier system coupled to a 150 KVA generator. Renew. Energy 2014, 71, 695-700. [CrossRef]

20. Melapi, A.; Mamphweli, S.N.; Katwire, D.M.; Meyer, E.L. The Physical and Chemical Properties of Fine Carbon Particles-Pinewood Resin Blends and Their Possible Utilization. J. Chem. 2015, 2015, 137580. [CrossRef]

21. Addepalli, S.; Eiroa, D.; Lieotrakool, S.; Francois, A.L.; Guisset, J.; Sanjaime, D.; Kazarian, M.; Duda, J.; Roy, R.; Phillips, P. Degradation study of heat exchangers. Procedia CIRP 2015, 38, 137-142. [CrossRef]

22. Pan, C.; Liang, Q.; Guo, X.; Dai, Z.; Liu, H.; Gong, X. Characteristics of Different Sized Slag Particles from Entrained-Flow Coal Gasification. Energy Fuels 2015, 30, 1487-1495. [CrossRef]

23. Lund, P.; Byrne, J.A.; Berndes, G.; Vasalos, I. Advances in Bioenergy: The Sustainability Challenge; John Wiley \& Sons: New York, NY, USA, 2015; ISBN: 1118957865, 9781118957868.

24. Demadis, K.D. Combating heat exchanger fouling and corrosion phenomena in process waters. In Compact Heat Exchangers and Enhancement Technology for the Process Industries; Begell House Inc.: Danbury, CT, USA, 2003; pp. 483-490.

25. Miller, F.P.; Vandome, A.F.; McBrewster, J. Carbon Black; German publishing group: Saarbrücken, Germany; ISBN: 6130702493.

(C) 2017 by the authors. Licensee MDPI, Basel, Switzerland. This article is an open access article distributed under the terms and conditions of the Creative Commons Attribution (CC BY) license (http:/ / creativecommons.org/licenses/by/4.0/). 